\title{
SIMULASI MCNP5 DALAM EKSPERIMEN KRITIKALITAS LARUTAN PLUTONIUM-URANIUM NITRAT DENGAN REFLEKTOR AIR DAN POLYETHYLENE
}

\author{
Dinan Andiwijayakusuma1, Topan Setiadipura1, Zuhair ${ }^{2}$ \\ $1_{\text {Bidang Komputasi }}$ \\ Pusat Pengembangan Informatika Nuklir - BATAN \\ 2Program Studi Teknik Informatika \\ Fakultas Ilmu Komputer - Universitas Mercu Buana
}

\begin{abstract}
ABSTRAK
SIMULASI MCNP5 DALAM EKSPERIMEN KRITIKALITAS LARUTAN PLUTONIUM DAN URANIUM NITRAT DENGAN REFLEKTOR AIR DAN POLYETHYLENE. Banyak perangkat kritik dibangun untuk memenuhi kebutuhan studi fenomena kecelakaan kritikalitas pada larutan fisil di fasilitas daur bahan bakar nuklir. Salah satu diantaranya adalah perangkat kritik SCAMP. Di perangkat ini dikerjakan eksperimen kritikalitas menggunakan bejana silindris stainless steel berisi larutan plutonium- uranium nitrat $(\mathrm{Pu}+\mathrm{U}$ nitrat). Sebanyak 7 eksperimen didemonstrasikan dengan reflektor air di semua sisi permukaan bejana larutan kecuali di bagian atas bejana. Makalah ini membahas simulasi transport Monte Carlo MCNP5 dalam eksperimen kritikalitas larutan Pu+U nitrat dengan reflektor air dan polyethylene. Simulasi MCNP5 dengan pustaka ENDF/B-VI memberikan hasil yang paling dekat dengan data eksperimen terutama pada kasus A untuk varian geometri 4. Dibandingkan pustaka ENDF/B-V, perhitungan kritikalitas dengan pustaka ENDF/B-VI memberikan hasil lebih dekat dengan perhitungan MONK dimana bias perhitungannya $<0,44 \%$, khususnya pada kasus A namun pada kasus B dan C simulasi MCNP5 dengan pustaka ENDF/B-V memberikan hasil dengan kecenderungan lebih baik dibandingkan pustaka ENDF/B-VI dengan bias perhitungan < $2,67 \%$ dan $<1,13 \%$. Secara keseluruhan dapat disimpulkan bahwa MCNP5 telah menunjukkan reliabilitasnya dalam simulasi kritikalitas larutan $\mathrm{Pu}+\mathrm{U}$ nitrat.
\end{abstract}

Kata kunci: kritikalitas, larutan Pu+U nitrat, ENDF/B-V, ENDF/B-VI, MCNP5

\begin{abstract}
MCNP5 SIMULATION IN CRITICALITY EXPERIMENT OF PLUTONIUM-URANIUM NITRATE SOLUTION WITH WATER AND POLYETHYLENE REFLECTORS. There are many critical assemblies have been built to meet the need of criticality accident phenomenon study on fissile solution at nuclear fuel cycle facilities. One of them is critical assembly SCAMP. In this assembly the criticality experiments were carried out by using stainless steel cylindrical vessel containing plutonium-uranium nitrate solution $(\mathrm{Pu}+\mathrm{U}$ nitrate). 7 Experiments have been demonstrated with water reflector at all surface areas of solution vessel except on the top vessel. This paper discusses simulation of Monte Carlo transport MCNP5 in criticality experiment of $\mathrm{P}+\mathrm{U}$ nitrates solution with water and polyethylene reflectors. Simulation MCNP5 with ENDF/B-VI library gives closest results with experimental data, especially in the case A for geometry variant 4 . Compared to ENDF/B-V library, criticality calculations with ENDF/B-VI library give closer results with MONK calculations where its calculation bias is $<0.44 \%$, especially in the case A but in the case B and C, MCNP5 simulation with ENDF/B-V library give results with a better tendency than ENDF/B-VI library with calculation biases of $<2.67 \%$ and $<1.13 \%$. All in all, it can be concluded that MCNP5 has indicated its reliability in criticality simulation of $\mathrm{Pu}+\mathrm{U}$ nitrate solution.
\end{abstract}

Keywords: criticality, Pu+U nitrate solution, ENDF/B-V, ENDF/B-VI, MCNP5 


\section{PENDAHULUAN}

Banyak perangkat kritik dibangun untuk memenuhi kebutuhan studi fenomena kecelakaan kritikalitas pada larutan fisil di fasilitas daur bahan bakar nuklir. Salah satu diantaranya adalah perangkat kritik SCAMP[1] (Solution Criticality Assembly Machine - Plutonium) di AWRE Aldermaston. Di perangkat ini dikerjakan eksperimen kritikalitas menggunakan bejana silindris stainless steel berisi larutan plutonium dan uranium nitrat $(\mathrm{Pu}+\mathrm{U}$ nitrat). Sebanyak 7 eksperimen didemonstrasikan dengan reflektor air di semua sisi permukaan bejana larutan kecuali di bagian atas bejana.

Makalah ini membahas simulasi transport Monte Carlo MCNP5[2] dalam eksperimen kritikalitas larutan $\mathrm{Pu}+\mathrm{U}$ nitrat dengan reflektor air dan polyethylene. Program MCNP dipilih karena banyak diaplikasikan dalam studi analisis fenomena nuklir di berbagai fasilitas nuklir seperti reaktor fisi[3-6], reaktor fusi[7-8] dan akselerator [9-10].
Komparasi simulasi MCNP5 dengan data eksperimen dan perhitungan Monte Carlo MONK juga didiskusikan dalam makalah ini. Analisis akurasi simulasi MCNP5 dalam eksperimen kritikalitas $\mathrm{Pu}+\mathrm{U}$ nitrat dikerjakan dengan memanfaatkan pustaka data tampang lintang energi kontinu ENDF/B-V[11] dan ENDF/B-VI[12].

\section{DESKRIPSI KONFIGURASI EKSPERIMEN}

Perangkat kritik untuk eksperimen kritikalitas didesain dengan bejana yang dapat dipertukarkan dengan sistem kendali yang sama. Eksperimen dilakukan dengan bejana silindris berjari-jari internal 12,75 $\mathrm{cm}, 15,31 \mathrm{~cm}$ dan 25,36 $\mathrm{cm}$. Dinding bejana memiliki ketebalan $0,2 \mathrm{~cm}$ untuk silinder yang paling kecil dan $0,25 \mathrm{~cm}$ untuk silinder lainnya. Variasi tinggi bejana adalah $107 \mathrm{~cm}$ dan 91,5 cm. Diagram skematik perangkat kritik larutan $\mathrm{Pu}+\mathrm{U}$ nitrat diperlihatkan dalam Gambar 1.

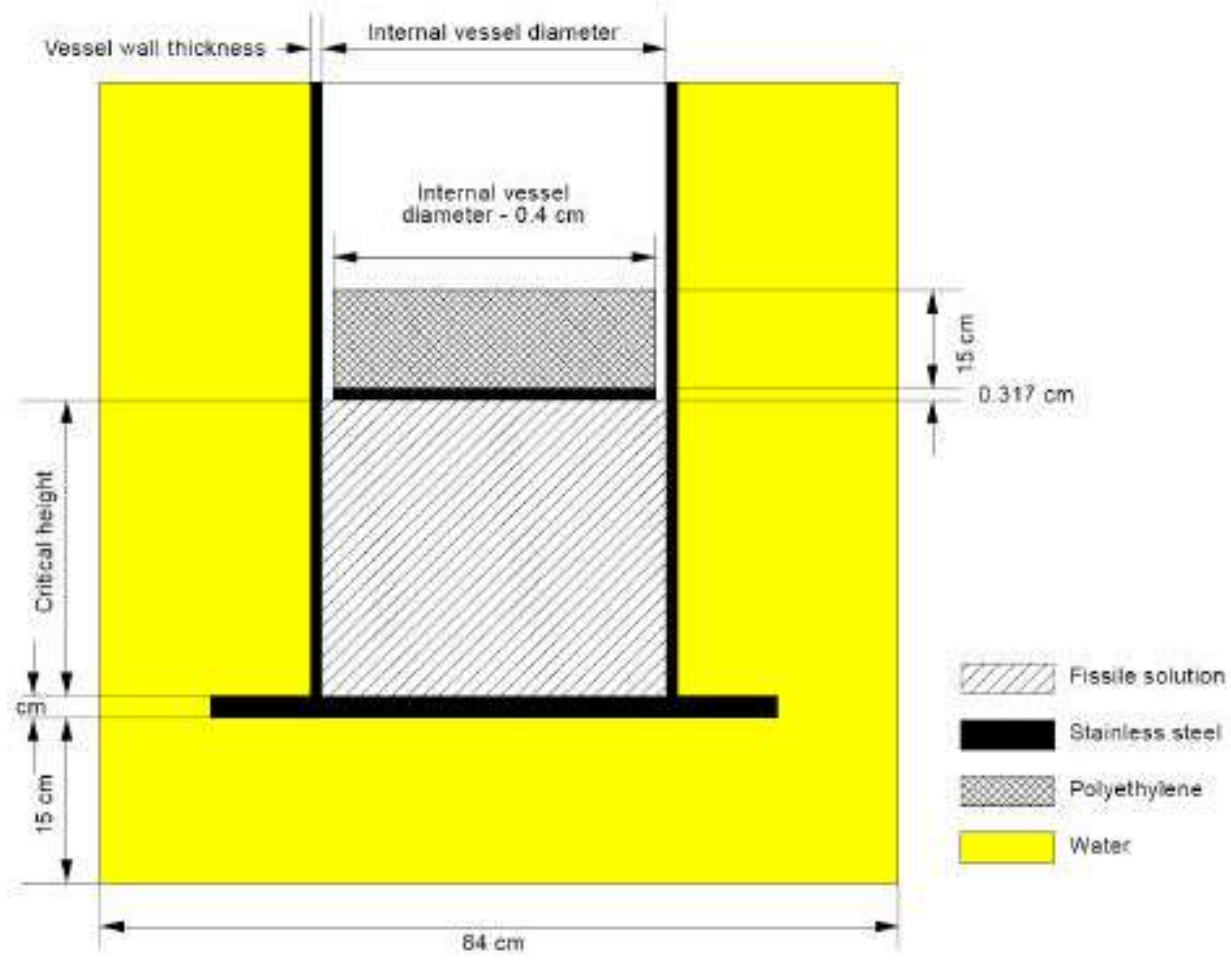

Gambar 1. Diagram skematik perangkat kritik larutan $\mathrm{Pu}+\mathrm{U}$ nitrat. 
Tabel 1. Geometri bejana eksperimen dan dimensi kritikalitas[1]

\begin{tabular}{|c|c|c|c|c|}
\hline Eksperimen & Larutan fisil & $\begin{array}{c}\text { Radius } \\
\text { internal bejana }(\mathrm{cm})\end{array}$ & $\begin{array}{c}\text { Tinggi } \\
\text { internal } \\
\text { bejana }(\mathrm{cm})\end{array}$ & $\begin{array}{c}\text { Ketinggian } \\
\text { kritis } \\
(\mathrm{cm})\end{array}$ \\
\hline 1 & A & $12,7125 \pm 0,005$ & 107,0 & $56,31 \pm 0,06$ \\
2 & A & $15,31 \pm 0,01$ & 107,0 & $29,89 \pm 0,05$ \\
3 & A & $18,995 \pm 0,04$ & 107,0 & $21,17 \pm 0,04$ \\
4 & A & $25,36 \pm 0,01$ & 91,5 & $16,05 \pm 0,04$ \\
\hline 5 & B & $18,995 \pm 0,04$ & 107,0 & $72,86 \pm 0,07$ \\
6 & B & $25,36 \pm 0,01$ & 91,5 & $33,59 \pm 0,03$ \\
\hline 7 & C & $25,36 \pm 0,01$ & 91,5 & $37,16 \pm 0,03$ \\
\hline
\end{tabular}

Tabel 2. Komposisi isotopik larutan $\mathrm{Pu}+\mathrm{U}$ nitrat $[1]$

\begin{tabular}{|c|c|c|}
\hline \multirow{3}{*}{ Plutonium } & $239 \mathrm{Pu}$ & $93,95(\mathrm{wt} \%)$ \\
& $240 \mathrm{Pu}$ & $5,63(\mathrm{wt} \%)$ \\
& $241_{\mathrm{Pu}}$ & $0,42(\mathrm{wt} \%)$ \\
\hline \multirow{2}{*}{ Uranium } & $235 \mathrm{U}$ & $0,72(\mathrm{wt} \%)$ \\
& $238 \mathrm{U}$ & $99,28(\mathrm{wt} \%)$ \\
\hline
\end{tabular}

Tangki aluminium berdiameter internal $84 \mathrm{~cm}$ disusun pada sistem perangkat untuk mempertahankan reflektor air dalam setiap eksperimen agar tetap memiliki ketebalan $15 \mathrm{~cm}$ di bawah teras. Plug (penyumbat) polyethylene setebal 15 $\mathrm{cm}$ diletakkan di atas larutan fisil untuk mempersembahkan reflektor bersifat hidrogen infinit secara efektif pada bagian atas permukaan larutan. Setiap plug mempunyai plat stainless steel setebal $0,317 \mathrm{~cm}$ di bagian bawah. Celah anular $0,2 \mathrm{~cm}$ antara plug dan bejana ditujukan untuk aliran udara dan untuk mengeluarkan larutan fisil. Teknik eksperimen terdiri atas pengukuran laju cacah neutron pada ketinggian demi ketinggian secara berurutan. Dengan menggunakan ekstrapolasi kuadrat terkecil (least square) dari kurva 1/cacah, ketinggian kritis dapat diprediksi. Geometri bejana eksperimen dan dimensi kritikalitas diberikan dalam Tabel 1. Komposisi isotopik larutan fisil disajikan dalam Tabel 2 dan deskripsi detail dari larutan $\mathrm{Pu}+\mathrm{U}$ nitrat disajikan dalam Tabel 3.

Tabel 3. Deskripsi larutan $\mathrm{Pu}+\mathrm{U}$ nitrat $[1]$

\begin{tabular}{|c|c|c|c|}
\hline Larutan & $\mathrm{A}$ & $\mathrm{B}$ & $\mathrm{C}$ \\
\hline $\mathrm{H} / \mathrm{Pu}($ atom$)$ & $224 \pm 1$ & $1372 \pm 5$ & $1461 \pm 6$ \\
\hline $\mathrm{N} / \mathrm{Pu}($ atom$)$ & $12,1 \pm 0,1$ & $20,2 \pm 0,2$ & $20,9 \pm 0,2$ \\
\hline $\begin{array}{c}\mathrm{Pu} /(\mathrm{Pu}+\mathrm{U}) \\
(\mathrm{wt} \%)\end{array}$ & $30,7 \pm 0,2$ & $30,6 \pm 0,2$ & $30,6 \pm 0,2$ \\
\hline Densitas $(\mathrm{g} / \mathrm{ml})$ & $1,524 \pm 0,001$ & $1,1185 \pm 0,001$ & $1,113 \pm 0,001$ \\
\hline Normalitas & $1,60 \pm 0,03$ & $0,95 \pm 0,03$ & $0,93 \pm 0,03$ \\
\hline \multicolumn{4}{|c|}{ Konsentrasi $(\mathrm{mg} / \mathrm{ml})$} \\
\hline $\mathrm{Pu}$ & $101,3 \pm 0,2$ & $18,61 \pm 0,07$ & $17,50 \pm 0,08$ \\
\hline $\mathrm{U}$ & $228,5 \pm 1$ & $42,2 \pm 0,1$ & $39,6 \pm 0,1$ \\
\hline $\mathrm{NO}_{3}$ & $319 \pm 3$ & $97,5 \pm 1$ & $94,7 \pm 1$ \\
\hline $\mathrm{H}_{2} \mathrm{O}$ & $857 \pm 2$ & $962 \pm 2$ & $963 \pm 2$ \\
\hline
\end{tabular}




\section{MODEL SIMULASI MCNP5}

Simulasi MCNP5 dalam eksperimen kritikalitas dilakukan dengan memodelkan geometri perangkat kritik larutan $\mathrm{Pu}+\mathrm{U}$ nitrat secara rinci. Perangkat kritik dimodelkan dengan menggenerasi sel yang dibatasi oleh permukaan dalam 3 dimensi. Sel kisi berbentuk silinder dibuat dengan jari-jari bervariasi yang diletakkan secara konsentris di dalam silinder berjarijari $42 \mathrm{~cm}$. Kedua silinder merepresentasikan bejana yang masing-masing diisi oleh air dan larutan fisil. Sel kisi silinder untuk merepresentasikan bejana yang diisi plug polyethylene dengan jari-jari kurang $0,2 \mathrm{~cm}$ dari jari-jari bejana larutan fisil juga dibuat dengan opsi yang sama.

Parameter model geometri yang digunakan dalam simulasi MCNP5 disajikan dalam Tabel 4. Densitas atom larutan fisil diberikan dalam Tabel 5 dan densitas atom material lainnya diberikan dalam Tabel 6.

Tabel 4. Parameter model geometri dalam simulasi MCNP5

\begin{tabular}{|c|c|c|c|c|}
\hline Eksperimen & $\begin{array}{c}\text { Radius } \\
\text { internal bejana } \\
(\mathrm{cm})\end{array}$ & $\begin{array}{c}\text { Tinggi } \\
\text { internal bejana } \\
(\mathrm{cm})\end{array}$ & $\begin{array}{c}\text { Tebal dinding } \\
\text { sisi bejana } \\
(\mathrm{cm})\end{array}$ & $\begin{array}{c}\text { Ketinggian } \\
\text { kritis } \\
(\mathrm{cm})\end{array}$ \\
\hline 1 & 12,7125 & 107,0 & 0,20 & 56,31 \\
2 & 15,31 & 107,0 & 0,25 & 29,89 \\
3 & 18,995 & 107,0 & 0,25 & 21,17 \\
4 & 25,36 & 91,5 & 0,25 & 16,05 \\
\hline 5 & 18,995 & 107,0 & 0,25 & 72,86 \\
6 & 25,36 & 91,5 & 0,25 & 33,59 \\
\hline 7 & 25,36 & 91,5 & 0,25 & 37,16 \\
\hline
\end{tabular}

Tabel 5. Densitas atom larutan $\mathrm{Pu}+\mathrm{U}$ nitrat (atom/barn-cm)

\begin{tabular}{|c|c|c|c|c|}
\hline Eksperimen & $239 \mathrm{Pu}$ & $240 \mathrm{Pu}$ & $241 \mathrm{Pu}$ & $235 \mathrm{U}$ \\
\hline 1 & $2,3960 \mathrm{E}-04$ & $1,4400 \mathrm{E}-05$ & $1,1000 \mathrm{E}-06$ & $4,2000 \mathrm{E}-06$ \\
2 & $2,3960 \mathrm{E}-04$ & $1,4400 \mathrm{E}-05$ & $1,1000 \mathrm{E}-06$ & $4,2000 \mathrm{E}-06$ \\
3 & $2,3960 \mathrm{E}-04$ & $1,4400 \mathrm{E}-05$ & $1,1000 \mathrm{E}-06$ & $4,2000 \mathrm{E}-06$ \\
4 & $2,3960 \mathrm{E}-04$ & $1,4400 \mathrm{E}-05$ & $1,1000 \mathrm{E}-06$ & $4,2000 \mathrm{E}-06$ \\
\hline 5 & $4,4000 \mathrm{E}-05$ & $2,6000 \mathrm{E}-06$ & $2,0000 \mathrm{E}-07$ & $7,6000 \mathrm{E}-07$ \\
6 & $4,4000 \mathrm{E}-05$ & $2,6000 \mathrm{E}-06$ & $2,0000 \mathrm{E}-07$ & $7,6000 \mathrm{E}-07$ \\
\hline 7 & $4,1400 \mathrm{E}-05$ & $2,5000 \mathrm{E}-06$ & $1,8000 \mathrm{E}-07$ & $7,6000 \mathrm{E}-07$ \\
\hline
\end{tabular}

Tabel 5. Densitas atom larutan $\mathrm{Pu}+\mathrm{U}$ nitrat (atom/barn-cm) (lanjutan)

\begin{tabular}{|c|c|c|c|c|}
\hline $238 \mathrm{U}$ & $\mathrm{H}$ & $\mathrm{N}$ & $\mathrm{O}$ & $\mathrm{Fe}$ \\
\hline $5,7390 \mathrm{E}-04$ & $5,7300 \mathrm{E}-02$ & $3,1000 \mathrm{E}-03$ & $3,8600 \mathrm{E}-02$ & $2,0000 \mathrm{E}-08$ \\
$5,7390 \mathrm{E}-04$ & $5,7300 \mathrm{E}-02$ & $3,1000 \mathrm{E}-03$ & $3,8600 \mathrm{E}-02$ & $2,0000 \mathrm{E}-08$ \\
$5,7390 \mathrm{E}-04$ & $5,7300 \mathrm{E}-02$ & $3,1000 \mathrm{E}-03$ & $3,8600 \mathrm{E}-02$ & $2,0000 \mathrm{E}-08$ \\
$5,7390 \mathrm{E}-04$ & $5,7300 \mathrm{E}-02$ & $3,1000 \mathrm{E}-03$ & $3,8600 \mathrm{E}-02$ & $2,0000 \mathrm{E}-08$ \\
\hline $1,0600 \mathrm{E}-04$ & $6,4300 \mathrm{E}-02$ & $9,5000 \mathrm{E}-04$ & $3,4900 \mathrm{E}-02$ & $4,0000 \mathrm{E}-09$ \\
$1,0600 \mathrm{E}-04$ & $6,4300 \mathrm{E}-02$ & $9,5000 \mathrm{E}-04$ & $3,4900 \mathrm{E}-02$ & $4,0000 \mathrm{E}-09$ \\
\hline $9,9500 \mathrm{E}-05$ & $6,4400 \mathrm{E}-02$ & $9,2000 \mathrm{E}-04$ & $3,4900 \mathrm{E}-02$ & $4,0000 \mathrm{E}-09$ \\
\hline
\end{tabular}


Tabel 6. Densitas atom material lainnya (atom/barn-cm)

\begin{tabular}{|c|c|c|}
\hline \multirow{2}{*}{ Stainless steel 304L } & $\mathrm{Fe}$ & $6,3287 \mathrm{E}-02$ \\
& $\mathrm{Cr}$ & $1,6534 \mathrm{E}-02$ \\
\hline \multirow{2}{*}{ Polyethylene } & $\mathrm{Ni}$ & $6,5093 \mathrm{E}-03$ \\
\hline \multirow{2}{*}{ Air } & $\mathrm{H}$ & $7,9867 \mathrm{E}-02$ \\
& $\mathrm{C}$ & $3,9933 \mathrm{E}-02$ \\
\hline & $\mathrm{H}$ & $6,6729 \mathrm{E}-02$ \\
& $\mathrm{O}$ & $3,3366 \mathrm{E}-02$ \\
\hline
\end{tabular}

\section{HASIL SIMULASI DAN DISKUSI}

Seluruh perhitungan dilakukan pada temperatur ruang $\left(26^{\circ} \mathrm{C}\right)$ dan data eksperimen kritikalitas $\left(k_{\text {eff }}\right)=1$. Hal penting yang diamati dalam simulasi MCNP5 dalam eksperimen ini adalah komposisi detail dari material struktur tidak diberikan dalam referensi eksperimen namun diasumsikan tidak akan berpengaruh terhadap hasil simulasi kritikalitas $\left(k_{\text {eff }}\right)$. Tangki luar berisi air tidak pula dimasukkan dalam model perhitungan dan setidaknya air lebih tebal dari $15 \mathrm{~cm}$ yang terpisah dari larutan fisil dipastikan tidak akan menghasilkan pengaruh yang perlu dipertimbangkan.

Dalam MCNP5, opsi KCODE sebagai kontrol kritikalitas diterapkan dan simulasi kritikalitas MCNP5 dieksekusi dengan 1.000 neutron per siklus untuk 1.010 siklus iterasi dimana 10 skipping siklus pertama dipancung untuk menghindari problema konvergensi sumber. Opsi KSRC dikerjakan untuk sumber neutron stabil yang diletakkan dalam larutan $\mathrm{Pu}+\mathrm{U}$ nitrat. Jumlah neutron aktif total yang disimulasikan adalah 1.000.000.

Data hamburan neutron termal S(a, B) untuk air ringan (LWTR01) dimasukkan dalam simulasi untuk mempertimbangkan interaksi neutron dengan hidrogen dalam larutan $\mathrm{Pu}+\mathrm{U}$ nitrat pada energi di bawah $\sim 4 \mathrm{eV}$. Kondisi vakum dikenakan pada batas luar sistem perangkat kritik.

Hasil simulasi MCNP5 dan komparasinya dengan perhitungan MONK disajikan dalam Tabel 7. Dari Tabel 7 dapat diperhatikan bahwa untuk perhitungan kritikalitas tujuh variasi geometri dan tiga variasi densitas larutan $\mathrm{Pu}+\mathrm{U}$ nitrat, pada kasus $\mathrm{A}$ hasil simulasi MCNP5 menghasilkan nilai $k_{\text {eff }}$ yang lebih mendekati data eksperimen $\left(k_{\text {eff }}=1\right)$ terutama untuk varian geometri 4 dengan pustaka ENDF/B-VI yang memperlihatkan bias hanya $0,01 \%$. Ini berarti MCNP5 menunjukkan akurasi yang cukup presisi dalam perhitungan kritikalitas perangkat kritik SCAMP. 
Tabel 7. Hasil simulasi MCNP5 ( $k_{\text {eff }}$ ) dan komparasinya dengan MONK

\begin{tabular}{|c|c|c|c|}
\hline $\begin{array}{c}\text { Kasus } \\
\text { simulasi }\end{array}$ & $\begin{array}{c}\text { MONK } \\
(\text { UKNDL })\end{array}$ & $\begin{array}{c}\text { MCNP5 } \\
\text { Pustaka ENDF/B-V }\end{array}$ & $\begin{array}{c}\text { MCNP5 } \\
\text { Pustaka ENDF/B-VI }\end{array}$ \\
\hline 1 & $1,0125 \pm 0,0011$ & $1,01635 \pm 0,00089$ & $1,00810 \pm 0,00093$ \\
& $(1,0000) \dagger$ & $(1,0038)$ & $(0,9956)$ \\
\hline 2 & $1,0094 \pm 0,0011$ & $1,01608 \pm 0,00090$ & $1,00693 \pm 0,00089$ \\
& $(1,0000) \dagger$ & $((1,0066)$ & $(0,9975)$ \\
\hline 3 & $1,0077 \pm 0,0011$ & $1,01510 \pm 0,00090$ & $1,00636 \pm 0,00090$ \\
& $(1,0000) \dagger$ & $(1,0073)$ & $(0,9987)$ \\
\hline 4 & $0,9995 \pm 0,0011$ & $1,01019 \pm 0,00089$ & $0,99986 \pm 0,00090$ \\
& $(1,0000) \dagger$ & $(1,0107)$ & $(1,0004)$ \\
\hline 5 & $0,9978 \pm 0,0011$ & $0,97115 \pm 0,00070$ & $0,96611 \pm 0,00070$ \\
& $(1,0000) \dagger$ & $(0,9733)$ & $(0,9682)$ \\
\hline 6 & $0,9944 \pm 0,0011$ & $0,98233 \pm 0,00075$ & $0,97629 \pm 0,00070$ \\
& $(1,0000) \dagger$ & $(0,9879)$ & $(0,9818)$ \\
\hline 7 & $0,9948 \pm 0,0011$ & $0,98359 \pm 0,00071$ & $0,97696 \pm 0,00069$ \\
& $(1,0000) \dagger$ & $(0,9887)$ & $(0,9821)$ \\
\hline
\end{tabular}

$\dagger$ Perhitungan MONK dinormalisasi menjadi 1,0000

Dapat kita perhatkan pula bahwa dibandingkan pustaka ENDF/B-V, perhitungan kritikalitas dengan pustaka ENDF/B-VI memberikan hasil lebih dekat dengan perhitungan MONK dimana bias perhitungannya $<0,44 \%$, khususnya pada kasus A namun pada kasus B dan C simulasi MCNP5 dengan pustaka ENDF/B-V memberikan hasil dengan kecenderungan lebih baik dengan bias perhitungan $<2,67 \%$ dan $<1,13 \%$.

\section{KESIMPULAN}

Simulasi transport Monte Carlo MCNP5 dalam eksperimen kritikalitas larutan $\mathrm{Pu}+\mathrm{U}$ nitrat telah dilakukan dengan reflektor air dan polyethylene. Pustaka data nuklir energi kontinu ENDF/B-V dan ENDF/B-VI dimanfaatkan untuk melengkapi analisis.

Simulasi MCNP5 dengan pustaka ENDF/B-VI memberikan hasil yang paling dekat dengan data eksperimen terutama pada kasus A untuk varian geometri 4 . Dibandingkan pustaka ENDF/B-V, perhitungan kritikalitas dengan pustaka ENDF/B-VI memberikan hasil lebih dekat dengan perhitungan MONK dimana bias perhitungannya $<0,44 \%$, khususnya pada kasus A namun pada kasus B dan C simulasi MCNP5 dengan pustaka ENDF/B-V memberikan hasil dengan kecenderungan lebih baik dibandingkan pustaka ENDF/B-VI dengan bias perhitungan $<2,67 \%$ dan $<1,13 \%$.

Secara keseluruhan dapat disimpulkan bahwa MCNP5 telah menunjukkan reliabilitasnya dalam simulasi kritikalitas larutan $\mathrm{Pu}+\mathrm{U}$ nitrat.

\section{DAFTAR PUSTAKA}

[1]. R.C. LANE and C. PARKER, "Measurement of the Critical Size of Solutions of Plutonium and Natural Uranium Nitrates with $\mathrm{Pu} / \mathrm{U}=0,3$ ”, AWRE, September 1999

[2]. F.B. BROWN, et al., "MCNP - A General Monte Carlo N-Particle Transport Code, Version 5", LA-UR03-1987, April 24, 2003

[3]. ÜNER COLAK, VOLKAN SEKER, "Monte Carlo Criticality Calculations for a Pebble Bed Reactor with MCNP”, Journal of Nuclear Science and Engineering, Vol. 149(2), February 2005

[4]. AKIRA KITAMURA, et.al., "Measurements and Analysis of Neutron Flux Distribution in UTRKINKI", Journal of Nuclear Science 
and Technology, Vol. 40 (5), May (2003) 349-355

[5]. HIROKI SONO, et.al., "Analyses of Criticality and Reactivity for TRACY Experiments Based on JENDL-3.2 Data Library", Proceedings of The 7-th International Conference on Nuclear Criticality Safety (ICNC'2003), Tokai, Japan, October 20-24, 2003

[6]. TAGOR M. SEMBIRING and ZUHAIR, "Criticality Safety Assessment on the RSG-GAS Fresh Fuel Storage for Anticipating the Next Core Conversion Program", Proceedings of The 8-th International Topical Meeting on Research Reactor Fuel Management (RRFM'2004), München, Germany, March 21-24, 2004

[7]. S. SATOH, H. IIDA, "ITER Shielding Analysis by 3D Monte Carlo Method, Present Status and Problems of Particle Simulation by Monte Carlo Method", Atomic Energy Society, Japan, 193, 2000

[8]. F. MAEKAWA, et.al., "Benchmark Experiment on Silicon Carbide with D-T Neutrons and Validation of Nuclear Data Libraries", Journal of
Fusion Engineering and Design, Vol. 58-59, p. 595-600, 2001

[9]. K. TUCEK, J. WALLENIUS, W. GUDOWSKI, "Coolant Void Worth in Fast Breeder Reactors and Accelerator-driven Transuranium and Minor-actinide Burners", Annals of Nuclear Energy, Vol. 31, (2004)1783-1801

[10]. MICHAEL PLASCHY, CHRISTOPHE DESTOUCHES, GERALD RIMPAULT and RAKESH CHAWLA, "Investigation of ADS-Type Heterogeneities in the MUSE4 Critical Configuration", Journal of Nuclear Science and Technology, Vol. 42 (9) September (2005)779-787

[11]. DLC-105/MCNPDAT: Standard Neutron Cross Section Data Library Derived from ENDF/B-V for MCNP Version 4, Radiation Shielding Center, 1994

[12]. J.S. HENDRICKS, S.C. FRANKLE, J.D. COURT, "ENDF/B-VI Data for MCNP", Los Alamos National Laboratory Report, LA-12891, 1994 